\title{
Effect of Research Methodology Workshop on the Perceptions of Post Graduate Medical Students towards Research
}

\author{
Leena Raveendra1 ${ }^{1}$ Sumanth Tarikere Parameshwaraiah ${ }^{2}$ \\ ${ }^{1}$ Assistant Professor, Department of Dermatology, Rajarajeswari Medical College and Hospital, Bangalore, \\ Karnataka, India. ${ }^{2}$ Associate Professor, Department of Psychiatry, Rajarajeswari Medical College and Hospital, \\ Bangalore, Karnataka, India.
}

\section{ABSTRACT}

\section{BACKGROUND}

Health research training is an important part of medical postgraduate program. There is a decrease in the number of students wanting to pursue a career in research-based activity. This can hamper the progress in the field of medicine. We wanted to assess the knowledge, attitude and practices of postgraduate medical students towards research before and after a workshop on research methodology.

\section{METHODS}

All the first year post graduate students of our medical college and hospital were invited for the study. A pre-test and post-test were administered to the students attending the workshop on research. Pretested and validated questionnaire contained questions on knowledge, attitude and practices was used. Paired t test and descriptive analysis were used for statistical analysis.

\section{RESULTS}

The mean score of knowledge was $3.39 \pm 0.98$ (48\%) during the pre-test and it was $3.73 \pm 1.22(53.93 \%)$ in the post test. Paired t test was significant. To assess the attitude, Likert scale was used with the options- strongly disagree, disagree, neutral, agree and strongly agree. When the pre-test and post-test attitude scores and practices were compared, t-value was significant. In the pre-test, $75 \%$ of the postgraduates wanted to pursue a career in research in the future, and it increased to $90.74 \%$ in the post test.

\section{CONCLUSIONS}

A focussed exposure and education about scientific research would enhance the knowledge, attitude and interest of students towards research and will provide better researchers for the future.

\section{KEY WORDS}

Postgraduates, Research, Knowledge, Attitude, Practices
Corresponding Author:

Sumanth Tarikere Parameshwaraiah, Associate Professor, Department of Psychiatry, Rajarajeswari Medical College \& Hospital, Kambipura, Mysore Road, Bangalore, Karnataka, India.

E-mail: sumanth_tp@yahoo.com

DOI: $10.14260 /$ jemds/2019/637

Financial or Other Competing Interests: None.

How to Cite This Article:

Raveendra L, Parameshwaraiah ST. Effect of research methodology workshop on the perceptions of post graduate medical students towards research. J. Evolution Med. Dent. Sci. 2019;8(39):2930-2933, DOI: 10.14260/jemds/2019/637

Submission 21-07-2019,

Peer Review 13-09-2019,

Acceptance 20-09-2019,

Published 30-09-2019.

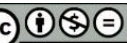




\section{BACKGROUND}

For the physician's evidence based practice, research experience becomes very important. Research experience helps a physician to analyse data and clinically appraise it. ${ }^{1}$ Also, research activity ensures better clinical care, critical reasoning, lifelong learning and future research activity. ${ }^{2}$ Research activity in any field is necessary for furthering the knowledge in that field. Research tries to find truth and it needs to be done systematically, in detail and in a very organised way. ${ }^{3}$ Progress in the field of medicine is due to what the researchers and scientists dedicated to research deliver. The training and performance of these scientists becomes very important for the progress that is achieved. ${ }^{4}$

The present generation of physician -scientists are ageing and reducing in number. So, to replace the present scientists and researchers working in the field of medicine we need young health professionals. ${ }^{3}$ But there is decrease in the number of students wanting to pursue a career in research activity. ${ }^{4}$ This can definitely hamper progress in medicine in the era of evidence based medicine. We need young doctors to take up an interest towards research. In a study done in India it was shown that only $0.5 \%$ of undergraduate students among over 100,000 showed any interest in research. This shows the poor inclination of the medical students towards research. These are the students who would further get into post graduate programs or become resident doctors. ${ }^{5}$ One of the factors for research not being a top career choice appears to be financial; like increasing cost of education and poor financial returns from research than in clinical careers. Research funding is also a factor. Decreasing of research budget and increased competition for funding contributes for research not being a top priority among young doctors. ${ }^{6}$ Research is not a popular career choice even in countries like United States where science is given a lot of importance. ${ }^{4}$ These aspects also need to be addressed if we have to attract young doctors to take up research.

Orientation towards research should be started early in the career of a health professional as this is important not only for the progress in the medical field but also helps them to understand how all the data from research emerges. This is how they can understand and practise evidence-based medicine. 4

Health research training is an important part of postgraduate program. Research activities have been introduced into the curricula of postgraduate students of medicine by Medical council of India. Medical council of India has also made it compulsory for post graduate students to present a poster and also a research paper, in either state, national or international conference. Post graduate students also have to send a paper for publication to a journal. ${ }^{7}$ This has forced the students to carry out some research. But till now there is no structured curricula for teaching them how to go about research related activity. Research training has still not become part of post graduate training. This has to be rectified.

There are many studies noting the knowledge attitude and practices of undergraduate students but the same in the post graduate students are very few. ${ }^{1}$ The present study was carried out to assess the research related knowledge, attitude, and practices of postgraduate students of a medical college and to know whether teaching the basics of research and making them aware of importance of research could change their research related behaviour.

\section{METHODS}

All post graduate medical students of first year admitted to our medical college and hospital in the year 2018 were invited for this study. A research methodology workshop is conducted for all the first-year students every year at our institute wherein they are taught about the basics of research so as to help in their dissertation and for help in further research activities. Research methodology workshop was conducted for 2 days. During the workshop postgraduates were taught about framing the research question, aims and objectives, literature search and basic statistical analysis. They were also introduced to the concept of funding for their research and various avenues to approach for funding. Various ethical issues involved in research were also dealt with. The workshop also included an interactive lecture on importance of research in medical field and how it would help them in their career.

A pre-test and post-test questionnaire were prepared after discussion with all the speakers. It was validated and pretested among the second- and third-year postgraduates. Institutional ethical committee clearance was obtained for the study.

This pretested questionnaire contained 7 multiple choice questions on knowledge, 7 on attitude where Likert scale was used, and 6 on practices with yes or no responses (Appendix 1). Among the 6 questions on attitude, the pre-test questionnaire had questions asking what their current practices were, while the post-test had questions asking what they would do in the future. It also had an item on positive interest or no interest to pursue a career in research and options to select the reason for the response.

This study was a quantitative interventional study. The statistical analysis used was paired t test and descriptive analysis.

\section{RESULTS}

A total of 68 first year post graduate students of our medical college and hospital attended the workshop. Before the questionnaires were administered, the students were told the purpose of the study. They were also informed that their participation was voluntary. We explained that we would require their names and that their responses would be kept confidential and used for research purposes only.

Of the 68 postgraduates about 61 students completed both the pre-test and the post-test questionnaire. They were given 20 minutes to complete the test, pre-test at the beginning of the workshop and post-test at the end of the workshop. The pre-test and post-test questionnaire completed by the postgraduates were corrected, tabulated and analysed.

The mean score of knowledge was $3.39 \pm 0.98(48 \%)$ during the pre-test and it was $3.73 \pm 1.22$ (53.93\%) in the post test (Figure 1). Paired t test was used to compare the scores, $t$ value was 2.33 and $p$ value was 0.02 which was 
significant. To assess the attitude, Likert scale was used with the options of strongly disagree, disagree, neutral, agree and strongly agree. To calculate the scores the options were given value of $1,2,3,4,5$ respectively and calculated. When compared with paired $t$ test for the pre-test and post test scores, $\mathrm{t}$ value was 2.66 and $\mathrm{p}$ value was 0.037 and was significant (Table 1). To assess the practice, the pre-test questionnaire had questions asking what their current practice was, while the post-test questionnaire had questions asking what they would do in the future. The positive responses of pre-test and post-test were compared by paired $t$ test wherein the value of $t$ was 3.366 and $p$ was 0.015 and was significant (Table 2). In the pre-test $75 \%$ of the postgraduates wanted to pursue a career in research in the future and it increased to $90.74 \%$ in the post test. The reason given in $69.69 \%$ and $73.4 \%$ of the postgraduates respectively in pre-test and post-test, for pursuing research was because it would elevate their personal standing as a clinician.

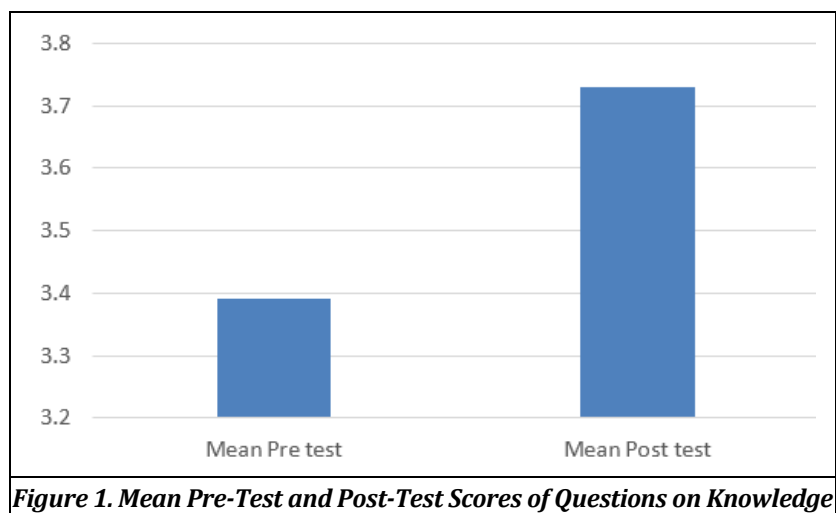

\begin{tabular}{|c|c|c|c|}
\hline & Questions of Attitude & $\begin{array}{c}\text { Pre-Test } \\
\text { Total Score }\end{array}$ & $\begin{array}{c}\text { Post-Test } \\
\text { Total Score }\end{array}$ \\
\hline Q 8 & Patient outcome improves with medical research? & 249 & 266 \\
\hline Q 9 & $\begin{array}{c}\text { Training in medical research methodology should } \\
\text { be made compulsory for postgraduates? }\end{array}$ & 232 & 257 \\
\hline Q 10 & $\begin{array}{c}\text { Undertaking research work increases burden on } \\
\text { already overworked doctors? }\end{array}$ & 168 & 183 \\
\hline Q 11 & $\begin{array}{c}\text { Postgraduate students need guidance and } \\
\text { supervision to conduct research project? }\end{array}$ & 285 & 280 \\
\hline Q 12 & $\begin{array}{c}\text { Research time should be allotted separately while } \\
\text { planning postgraduate curriculum? }\end{array}$ & 263 & 259 \\
\hline Q 13 & $\begin{array}{c}\text { Research is important for updating knowledge in } \\
\text { medicine }\end{array}$ & 269 & 306 \\
\hline Q 14 & Research helps in professional enhancement & 261 & 284 \\
\hline \multicolumn{3}{|c|}{ Table 1. Pre-Test and Post-Test Scores of Questions of Attitude } \\
\hline \multicolumn{4}{|c|}{}
\end{tabular}

\begin{tabular}{|c|c|c|c|c|}
\hline & Pre-Test Questions & $\begin{array}{c}\text { Positive } \\
\text { Response }\end{array}$ & Post test Questions & $\begin{array}{l}\text { Positive } \\
\text { Response }\end{array}$ \\
\hline Q15 & $\begin{array}{c}\text { Do you have experience } \\
\text { of writing research } \\
\text { paper? }\end{array}$ & 8 & $\begin{array}{c}\text { Are you willing to do } \\
\text { scientific research and } \\
\text { write a research paper? }\end{array}$ & 54 \\
\hline Q16 & $\begin{array}{c}\text { Do you have publications } \\
\text { in journals? }\end{array}$ & 6 & $\begin{array}{c}\text { Do you want to publish in } \\
\text { journals? }\end{array}$ & 56 \\
\hline Q17 & \begin{tabular}{|c|} 
Have you presented \\
poster or research paper \\
in a conference?
\end{tabular} & 3 & $\begin{array}{c}\text { Do you want to present } \\
\text { poster or research paper in } \\
\text { a conference? } \\
\end{array}$ & 56 \\
\hline Q18 & $\begin{array}{c}\text { Do you read journals } \\
\text { regularly? }\end{array}$ & 21 & $\begin{array}{c}\text { Are you willing to read } \\
\text { journals regularly? }\end{array}$ & 56 \\
\hline Q19 & \begin{tabular}{|c|} 
Are you willing to \\
continue doing research \\
other than thesis work?
\end{tabular} & 46 & $\begin{array}{l}\text { Are you willing to continue } \\
\text { doing research other than } \\
\text { thesis work? }\end{array}$ & 52 \\
\hline Q20 & $\begin{array}{c}\text { Are you willing to attend } \\
\text { workshops to enhance } \\
\text { your research skills? }\end{array}$ & 57 & $\begin{array}{l}\text { Are you willing to attend } \\
\text { workshops to enhance } \\
\text { your research skills? }\end{array}$ & 58 \\
\hline \multicolumn{5}{|c|}{$\begin{array}{c}\text { Table 2. Positive Response to Questions on Practices in Pre-Test and } \\
\text { Post-Test }\end{array}$} \\
\hline
\end{tabular}

\section{DISCUSSION}

Progress in field of medicine is dependent on what the scientists dedicated to research in medical field can deliver. There is a need for young doctors to develop interest in research and later pursue it, but as we see today there is reduction in the number of students pursuing a career in medical research. ${ }^{3}$ The same trend is noted in India also.

In India, for postgraduates, dissertation is an important part for completing the postgraduate programme. They not only have to do an original research and submit a thesis but have to present papers in conference and send papers for publication. ${ }^{7}$ This is a mandatory requirement for completion of the post graduate course. This has been implemented so as to nurture research mindedness in young doctors.

In our study, the mean score of knowledge was $3.39 \pm 0.98$ (48\%) during the pre-test. The mean score of knowledge was $3.73 \pm 1.22(53.93 \%)$ in the post test. The knowledge about research in our postgraduates was similar to another study in post graduate trainees in Pakistan where the mean score of knowledge was 36.9\%. ${ }^{1}$ In an Indian study by Pawar DB, they found that the knowledge about the need and prerequisites of research was good in the postgraduate trainees. 5

The knowledge about research in the postgraduates of our study significantly improved after the workshop on research methodology. This indicates that, training the postgraduates does improve their knowledge and thereby might increase their interest in research. At present we only have a workshop of two days to train the residents in our institute. This is not adequate to teach all the nuances of research. They need to first frame a research question and come up with aims and objectives that will be studied in the course of the research. Framing a proper research question itself requires a lot of guidance.

Biostatistics is one of those areas of research in which most doctors feel that they are in unfamiliar territory. This was reported in a study in Saudi Arabia. In kingdom of Saudi Arabia medical biostatistics is a premedical course of one year and passing it is a requirement. Even with this requirement physician do not have adequate knowledge about biostatistics. They also report that only courses in biostatistics did not enhance their knowledge in research but by fusing the biostatistics with epidemiology and research methodology enhanced their research mindedness and so was able to lead to good quality research and good patient care decisions. ${ }^{8}$

The mean attitude score was $69 \pm 25$. $29(65.98 \%)$ in the pre-test which was better than the knowledge score. The score on attitude in our residents was more than another study by Hassan Khan where the attitude score was $47 \%{ }^{1}$ Pawar DB also reports that the attitude about research was good in their post graduate residents. ${ }^{5}$ As seen by the pre-test the attitude in the residents towards research is already good and if driven in the right direction we could have good researchers in the future. The attitude score increased significantly after the workshop in our residents.

In our study, $90 \%$ of the students were willing to do research. In an American study on family practice residents $85 \%$ of them thought that research experience was desirable and $48 \%$ wanted to pursue research during residency. ${ }^{9}$ In another study by Moraes on undergraduates, $81.7 \%$ of the respondents declared they had an interest in research during their undergraduate training. ${ }^{4}$ Both these studies are concordant with our study wherein the young doctors are willing to do research. In contrast in a study on Canadian 
family physicians, most of the physicians believed that research was important in principle only. They did not believe that they should have good research skills nor have research education during residency. ${ }^{10}$

In the pre-test, $75 \%$ of the postgraduates wanted to pursue a career in research in the future and the percent increased to $90.74 \%$ in the post test and the reason given in $69.69 \%$ and $73.4 \%$ of the post graduates respectively in pretest and post-test, for pursuing research was because it would elevate their personal standing as a clinician. This indicated that our young postgraduates are interested to do research but the reason for it was to become better clinicians making better clinical judgement. Very few students wanted to pursue research to make advances in the field of medicine. We even after the workshop failed to impress our students to take up research find new innovations and advancement in our medical field. This indicates that there is a need to further educate the medical students be it undergraduates or postgraduates about the role research plays in advancement in medical field. Young minds should be pushed in the right direction so as to make research a part of their career and not just to reap the benefits of others works.

The research activity in most postgraduates stops usually at the mandatory research required to complete their course. Even though many residents showed interest in research only few of them were actually involved in active research in the study by Pawar DB and the reason given was lack of time and lack of research curriculum. Together with the busy schedule of clinical and other academic work they have to make time for research which many times is not very rewarding. ${ }^{5}$ Lack of time was the reason given by residents in the study by Hassan Khan in Pakistan for not able to pursue research activities. ${ }^{1}$ In another study on surgery and anaesthesia residents in Uganda majority had a positive attitude toward research and wanted to publish their study. Of these only $52 \%$ felt that they had been guided adequately. ${ }^{11}$ This aspect has been discussed in a study in Iran where they have brought out the complexities in research supervision. They feel that more attention needs to be given to the planning and the supervision of research. Quality of the research supervisors, the time that they can spare for the guidance and the lack of enough research knowledge in the supervisors were noted as barriers for conducting research. The other problems noted were lack of resources, incompetence of the students and supervisor student's relations. ${ }^{12}$ We were not able to explore this in our study because our study included only the first-year postgraduates. Further following up our residents would give us a better picture.

\section{CONCLUSIONS}

We feel that most of the postgraduates have the correct attitude towards research. They are interested in research activities, but they need to have proper guidance, resources and dedicated time to do their research related work in their busy schedule. They need to be trained adequately to conduct research activities. The professors and supervisors of these post graduate students must be trained adequately so as to be able to deal with any complexities of research. Research culture if incorporated early will provide better researchers and much needed developments in the field of medicine.

\section{REFERENCES}

[1] Khan H, Khan S, Iqbal A. Knowledge, attitudes and practices around health research: the perspective of physicians-in-training in Pakistan. BMC Med Educ 2009;9:46.

[2] Srinivasan MR, Poorni S, Sujatha G, et al. Research experiences, attitudes and barriers to publishing among the dental postgraduate teachers: a crosssectional study. Indian J Dent Res 2014;25(4):454-8.

[3] Siamian H, Mahmoudi R, Habibi F, et al. Students' attitudes towards research at Mazandaran University of Medical Sciences in 2015. Mater Sociomed 2016;28(6):468-72.

[4] Moraes DW, Jotz M, Menegazzo WR, et al. Interest in research among medical students: challenges for the undergraduate education. Rev Assoc Med Bras 2016;62(7):652-8.

[5] Pawar DB, Gawde SR, Marathe PA. Awareness about medical research among resident doctors in a tertiary care hospital: a cross-sectional survey. Perspect Clin Res 2012;3(2):57-61.

[6] HarshaKumar H, Jayaram S, Kumar GS, et al. Perception, practices towards research and predictors of research career among UG medical students from coastal South India: a cross-sectional study. Indian J Community Med 2009;34(4):306-9.

[7] Giri PA, Bangal VB, Phalke DB. Knowledge, attitude and practices towards medical research amongst the postgraduate students of Pravara Institute of Medical Sciences University of Central India. J Fam Med Primary Care 2014;3(1):22-4.

[8] Alzahrani SH, Aba Al-Khail BA. Resident physician's knowledge and attitudes toward biostatistics and research methods concepts. Saudi Med J 2015;36(10):1236-40.

[9] Temte JL, Hunter PH, Beasley JW. Factors associated with research interest and activity during family practice residency. Fam Med 1994;26(2):93-7.

[10] Leahy N, Sheps J, Tracy CS, et al. Family physicians' attitudes toward education in research skills during residency: findings from a national mailed survey. Can Fam Physician 2008;54(3):413-4.

[11] Elobu AE, Kintu A, Galukande M, et al. Research in surgery and anesthesia: challenges for post-graduate trainees in Uganda. Educ Health (Abingdon) 2015;28(1):11-5.

[12] Yousefi A, Bazrafkan L, Yamani N. A qualitative inquiry into the challenges and complexities of research supervision: viewpoints of postgraduate students and faculty member. J Adv Med Educ Prof 2015;3(3):91-8. 